\title{
Conjugative plasmidic AmpC detected in Escherichia coli, Proteus mirabilis and Klebsiella pneumoniae human clinical isolates from Portugal
}

\author{
Gabrielli Stefaninni Santiago ${ }^{1}$ (D) $\cdot$ Daniela Gonçalves ${ }^{2,3} \cdot$ Irene da Silva Coelho ${ }^{1} \cdot$ Shana de Mattos de Oliveira Coelho ${ }^{1}$. \\ Helena Neto Ferreira ${ }^{2}$
}

Received: 7 May 2020 / Accepted: 29 July 2020 / Published online: 1 August 2020

(C) Sociedade Brasileira de Microbiologia 2020

\begin{abstract}
AmpC is a type of $\beta$-lactamase enzyme produced by bacteria; these enzymes are classified in Class $C$ and Group 1 , and these confer resistance to cephamycin. Enterobacterales producing $\mathrm{AmpC}$ are reported worldwide and have great clinical importance due to therapeutic restriction and epidemiological importance once the easy dissemination by plasmidic genes to other bacteria is a real threat. These genes are naturally found in some enterobacteria as Enterobacter cloacae, Morganella morganii, and Citrobacter freundii, but other species have demonstrated similar resistance phenotype of AmpC production. Genes carried in plasmids have been described in these species conferring resistance to cefoxitin and causing therapeutic failure in some bacterial infections. This work detected and described five clinical strains of Escherichia coli, Proteus mirabilis, and Klebsiella pneumoniae that presented plasmid ampC (pAmpC) isolated from the north of Portugal collected in 2009. AmpC production was confirmed by inhibition of the enzyme by cloxacillin and boronic acid in agar diffusion tests. Also, PCR (polymerase chain reaction) was performed for the detection of gene universal to AmpC, bla $a_{\mathrm{ampC}}$, and others to AmpC group: bla $a_{\mathrm{ACC}}$, bla $_{\mathrm{CIT}}$, $b l a_{\mathrm{CMY}}, b l a_{\mathrm{DHA}}$, and $b l a_{\mathrm{EBC}}$. The conjugation in liquid medium for $24 \mathrm{~h}$ was realized to determine if gene is localized in chromosome or plasmid. The isolates and their conjugants showed phenotypic characteristics and $b l a_{\mathrm{CMY}}$ and $b l a_{\mathrm{CIT}}$ were detected by PCR corroborating the AmpC characteristics observed in these bacteria. Confirmation of transfer of plasmid containing genes encoding $\mathrm{AmpC}$ is of high epidemiological relevance to the hospital studied and demonstrated the importance of AmpC surveillance and studies in hospital and community environments in order to choose the appropriate therapy for bacterial infections.
\end{abstract}

Keywords $\beta$-Lactamase $\cdot$ Boronic acid $\cdot$ Cloxacillin $\cdot$ Conjugative plasmid $\cdot$ Nosocomial infection

Responsible Editor: Ana Lucia da Costa Darini.

Gabrielli Stefaninni Santiago

gabriellissantiago@outlook.com

1 Department of Veterinary Microbiology and Immunology, Universidade Federal Rural do Rio de Janeiro, BR 465, Km 07, Seropédica, RJ, Brazil

2 Laboratory of Biological Science 18.P5.E3, Faculty of Pharmacy of Universidade do Porto Porto and UCIBIO, Jorge Viterbo Ferreira, 228, Porto, Portugal

3 ISAVE - Instituto Superior de Saúde, Castelo de Almourol, 13 Apartado 49, Amares, Portugal

\section{Introduction}

Escherichia coli, Klebsiella pneumoniae, and Proteus mirabilis are the main Gram-negative pathogens responsible for nosocomial infections, a serious public health problem. Some risk factors in the development of these infections are burns, presence of endotracheal tubes, nasal tubes, blood catheters, and hospitalization for more than 2 weeks [1, 2]. In addition to the high rates of infection in hospitals, the growing resistance of these nosocomial pathogens to antimicrobials has an economic burden in the treatment of these infections. These pathogens have been reported resistant to important drugs to treat infectious diseases as cefotaxime, amoxicillin, nitrofurantoin, and trimethoprim plus sulfamethoxazole $[3,4]$. 
Multidrug-resistant microorganisms (MDR), in particular, Gram-negative MDR bacteria, are an increasing problem in hospital care around the world. The rate of antibiotic resistance among enterobacteria has accelerated dramatically in recent years and has reached a pandemic scale, due to the great diversity of mechanisms of resistance to existing antibiotics. It is no longer uncommon to find infections caused by bacteria with multiple resistance mechanisms. In recent years, new types of ESBL, AmpC, and carbapenemases $\beta$-lactamases have emerged [4].

Beta-lactamases are enzymes that cause resistance to $\beta$ lactams antibiotics, specifically by hydrolysis of the $\beta$ lactam ring. Ambler and Bush-Jacoby-Medeiros classified $\beta$-lactamases according to its function and molecular structure. AmpC $\beta$-lactamases belong to Class $\mathrm{C}$ and Group 1, according to Ambler and Bush-Jacoby-Medeiros, respectively. These enzymes confer resistance to cephamycin as cefoxitin to the oxyimino-cephalosporins (ceftazidime and cefotaxime, for instance), and these are not inhibited by clavulanate, sulbactam, and tazobactam. Boronic acid and cloxacillin are considered AmpC inhibitors used in phenotypical tests to confirm the enzyme presence [5-9].

Chromosomal AmpC is naturally found in group II Enterobacteriaceae (like Enterobacter spp., Serratia spp., Providentia spp., Morganella morganii, Citrobacter freundii, and Hafnia alvei). The most common plasmid-encoded AmpC (pAmpC) enzymes are CIT, CMY, and DHA. Other pAmpC can also found in Enterobacterales as EBC, FOX, and MOX. Originally, these genes were transferred by natural producers as described previously to another bacteria. Actually, these genes are disseminated between non-natural producers by plasmids or other mobile elements. Some authors describe that $\mathrm{pAmpC}$ can also confer resistance to carbapenems associated to the loss of outer membrane porin proteins in clinical isolates of Klebsiella pneumoniae and Salmonella enterica $[7,9,10]$.

The Centers for Disease Control and Prevention (CDC) and the World Health Organization (WHO) have designated $\beta$-lactamase-producing Gram-negative bacteria some of the world's most serious or critical threats [9].

AmpC-producing Enterobacterales studies have become important to understand the possibilities to treatment failures. Until 2012, AmpC production was rarely reported in the literature in both community and hospital cases [11]. Currently, this study has demonstrated that plasmid-mediated AmpC (pAmpC) is most detected in community-acquired infections, while cromossomal AmpC (cAmpC) producers are mainly involved in healthcare-associated infections [12-14].

The main goal of this work was to confirm AmpC production in clinical strains isolated from patients in hospitals in the north of Portugal before 2010 [15] and demonstrate the possibility of this mechanism of resistance being mediated by conjugative plasmids, leading to treatment failure in nosocomial infections.

\section{Materials and methods}

\section{Identification and antimicrobial susceptibility test}

Five strains previously identified and resistant to cefoxitin were used in this study. These bacteria were isolated from hospitals in the north of Portugal in 2009. They were maintained to $-80{ }^{\circ} \mathrm{C}$ until the use in this work. The isolates were grown on brain and heart infusion agar (BHIA) (Liofilchem) and incubated at $35^{\circ} \mathrm{C}$ for $24 \mathrm{~h}$. After this period, they were seeded on MacConkey agar (Liofilchem) and incubated in the same conditions for subsequent phenotypic confirmation of colonies characteristics. From this growth, the isolates were inoculated in trypticase soy broth (TSB) (Liofilchem). Identification was confirmed using Chromagar Orientation (CHROMagar) and ID32GN (Biomérieux).

These isolates were submitted to disk diffusion test to confirm phenotypic characteristics and confirm AmpC production using amoxicillin (AMO $10 \mu \mathrm{g}$ ), amoxicillin with clavulanate (AMC 20/10 $\mu \mathrm{g}$ ), aztreonam (AZT $30 \mu \mathrm{g}$ ), cefepime (CEF $30 \mu \mathrm{g}$ ), cefotaxime (CTX $30 \mu \mathrm{g}$ ), cefoxitin (FOX $30 \mu \mathrm{g}$ ), ceftazidime (CAZ $30 \mu \mathrm{g}$ ), imipenem (IMI $10 \mu \mathrm{g}$ ), and streptomycin (STP $10 \mu \mathrm{g}$ ) (Oxoid; Sensidisc) [16].

\section{AmpC inhibition by cloxacillin and boronic acid}

The cloxacillin inhibition method was performed using Muller-Hinton agar (MHA) added to cloxacillin $(200 \mu \mathrm{g} / \mathrm{mL}$ Sigma-Aldrich) to disk diffusion method, as described previously. It was positive when isolates demonstrated susceptibility to the antimicrobials to which were resistant in the method without cloxacillin $[6,8]$.

In boronic acid test, $400 \mu \mathrm{g}$ of boronic acid was added to cefoxitin disks. The isolates were inoculated in the MHA plate, and one disk with and one without boronic acid were added on each plate. Those isolates in which an increase in the diameter of the disk halo containing boronic acid was a value equal to or greater than $5 \mathrm{~mm}$ was observed, the isolate was considered to produce AmpC [5] (Fig. 1).

\section{Conjugation method}

This methodology was standardized by Mota (17) and was carried out with minor modifications. Firstly, the donor is prepared to conjugation method. This preparation involves three steps of bacterial culture, one in solid medium and two in liquid medium. The donor isolates were inoculated in CLED agar, and after $24 \mathrm{~h}, 35^{\circ} \mathrm{C}$, one colony of each isolate was suspended in $2 \mathrm{~mL}$ of TSB containing one disk of cefoxitin $30 \mu \mathrm{g}$. This broth was incubated at $35^{\circ} \mathrm{C}$ for $24 \mathrm{~h}$ and after this period $200 \mu \mathrm{L}$ was added to $2 \mathrm{~mL}$ of TSB without antimicrobial disk and incubated to the same period and temperature mentioned before. 


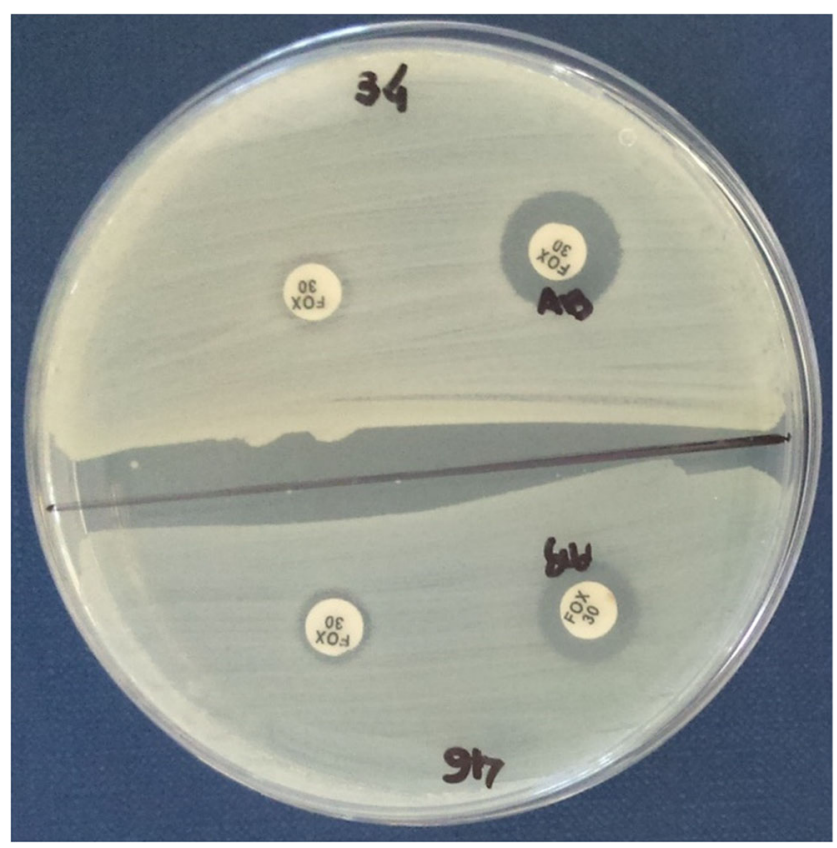

Fig. 1 Phenotypic test using boronic acid to detection of AmpC producing in Enterobacteriales. Example of isolates tested to AmpC inhibition by boronic acid (AB). Right disks of cefoxitin were added boronic acid $(\mathrm{AB})$ solution and left ones, no. It is possible to note increase in halo around $\mathrm{AB}+$ cefoxitin disk comparing with no added disk

The receptor strain used in the conjugation is Escherichia coli HB101. This strain was inoculated in CLED agar and after $24 \mathrm{~h}, 35^{\circ} \mathrm{C}$, one colony was suspended in $5 \mathrm{~mL}$ of TSB without cefoxitin disk. These culture mediums were inoculated at $35^{\circ} \mathrm{C}$ for $24 \mathrm{~h}$ to be used in mating.

In $2 \mathrm{~mL}$ of TSB without cefoxitin were added $200 \mu \mathrm{L}$ of donor bacteria broth (the second growth) and $400 \mu \mathrm{L}$ of receptor bacteria broth. The donor broth and the receptor broth used were prepared as mentioned previously. This suspension was incubated at $35^{\circ} \mathrm{C}$ for $24 \mathrm{~h}$ without shaking. The presence of transconjugants was observed in selective MacConkey agar plates with cefoxitin $(10 \mu \mathrm{g} / \mathrm{mL}$ Labesfal $)$ and streptomycin (100 $\mathrm{\mu g} / \mathrm{mL}$ Sigma-Aldrich) - presenting lactose nonfermenting colonies after incubation at $35^{\circ} \mathrm{C}$ for $24 \mathrm{~h}$.

From this bacterial growth in the selecting agar for transconjugants, five colonies for each tested strain were selected to verify the phenotypic and genotypic characteristics using the same methodologies described to detection and confirmation of AmpC performed in donor strains.

\section{PCR assays}

To obtain genomic DNA, a loopful of each pure isolate culture was suspended in $300 \mathrm{~mL}$ of sterile distilled water and was boiled for $10 \mathrm{~min}$. After $5 \mathrm{~min}$ of centrifugation, the supernatant was used as a DNA template for PCR amplification [17, $18]$.
The detection of $a m p C$ was performed firstly to universal blaAmpC [19]. The specific groups of AmpC were tested in multiplex PCR using primers to CIT, ACC, EBC, FOX, and MOX genes [20]. The PCR for DHA [21] and CMY [22] were performed using uniplex PCR.

Each reaction for uniplex PCR contained $20 \mathrm{mM}$ Tris- $\mathrm{HCl}$, $\mathrm{pH} 8.4 ; 50 \mathrm{mM} \mathrm{KCl}, 0.2 \mathrm{mM}$ of each dNTP, $1.5 \mathrm{mM} \mathrm{MgCl}$; $0.6 \mu \mathrm{M}$ of each primer; and $1.25 \mathrm{U}$ of Taq DNA polymerase (Kapa Biosystems) in a total reaction volume of $25 \mu \mathrm{L}$ containing $2 \mu \mathrm{L}$ of the extracted DNA [19, 21, 22]. The concentrations of primers used for multiplex amplification were as described by Pérez-Pérez and Hanson [20]. The thermal cycler T100TM Thermal Cycler (BIO-RAD) was used for PCR reactions and the products were evaluated by electrophoresis on agarose gel (2\%) (GeneON), revealed with Midori Green Advance DNA Stain (Nippon Genetics) and the molecular weight markers of $100 \mathrm{pb}$ (GRISP) and $1000 \mathrm{pb}$ (Bioron). The gels were registered using a BIO-RAD photo-documenter (Molecular Imager Gel Doc TM XR + System with Image LabTM Software, BIO-RAD).

\section{Control strains and receptor strain to conjugation method}

Escherichia coli CMY-2 positive was used as a control to tests performed in this work [23], Escherichia coli NCTC 13451 were used as negative control in this work, and Escherichia coli $\mathrm{HB} 101$ was used as receptor in conjugation.

\section{Results and discussion}

The isolates studied in this work were collected from clinical samples obtained in hospitals in north of Portugal in 2009 to evaluate other $\beta$-lactamases types. These five isolates demonstrate resistance to cefoxitin, characteristic of AmpC producers according to CLSI [16], but this enzyme was not evaluated at the time. The species presenting this resistance have been considered important species to nosocomial infections: Escherichia coli, Proteus mirabilis, and Klebsiella pneumoniae and these bacteria are commonly associated with multidrug-resistance $[3,4,15]$. K. pneumoniae $(3 / 5)$ was obtained from pus and urine, E. coli $(1 / 5)$ also was obtained from urine, and $P$. mirabilis (1/5) was isolated from a blood catheter. According to dates described by Goossens and Grabein (2005) [24], the prevalence of AmpC in the Europe was observed in Enterobacter spp. and Citrobacter spp. Both species are natural producers of $\mathrm{AmpC}$, different from the species mentioned in this work.

The bacteria selected with AmpC characteristics were submitted to the disk diffusion using $\beta$-lactams antibiotics to confirm the profile evaluated in 2009 . The resistance profile was confirmed; the isolates presented resistance to 
amoxicillin, amoxicillin with clavulanate, cefoxitin, ceftazidime, ceftriaxone, cefepime, and imipenem (Table 1). AmpC enzyme confers resistance to oxyiminocephalosporins and cephamycin, and it is not inhibited by clavulanate. Cefepime and imipenem resistance detected in Proteus mirabilis can be caused by the association of AmpC production and loss of outer membrane porin proteins [25]. Proteus spp. have been reported as a nosocomial bacteria arboring multidrug resistance gene in addition to the natural mechanisms found in this type of bacteria. The increase in multidrug resistance in Enterobacterales and limitation of options for antibiotic treatment is a significant public health issue $[26,27]$.

Coudron, Rodríguez-Martínez et al., and Pires et al. [5, 6, 8] describe that the AmpC enzyme is inhibited by boronic acid and cloxacillin. It was tested in our isolates, and boronic acid demonstrated to be a suitable inhibitor of resistance. Considering cloxacillin, it was not possible to observe AmpC inhibition in Escherichia coli and Proteus mirabilis, respectively. This observation was reported in transconjugants as described posteriorly.

Genotypically, the isolates amplified to $b l a_{\mathrm{ampC}}(5 / 5), b l a_{\mathrm{CIT}}$ $(3 / 5), b_{\mathrm{CMY}}(2 / 5)$, and $b l a_{\mathrm{DHA}}(2 / 5)$. These genes are described in plasmids in Escherichia coli, Proteus mirabilis, and Klebsiella pneumoniae. Reuland et al. [28] described in their study pAmpC $\left(\right.$ bla $_{\mathrm{CMY}}$, bla $_{\mathrm{MOX}}, b l a_{\mathrm{FOX}}, b l a_{\mathrm{DHA}}, b l a_{\mathrm{ACT}}, b l a_{\mathrm{MIR}}$, and $\left.b l a_{\mathrm{ACC}}\right)$ in community strains in Amsterdam. Ribeiro et al. [15] and Kazemian et al. [29] identified $b l a_{\mathrm{DHA}} b l a_{\mathrm{CMY}}$ and $b l a_{\mathrm{CIT}}$
pAmpC in Klebsiella pneumoniae, Escherichia coli, and Proteus mirabilis in different types of nosocomial infections in Portugal and Iran, respectively.

As has been observed by several previous studies, there is difficulty identifying AmpC production and identifying the specific type of AmpC enzyme produced by the isolate. This is maybe due to the different AmpC type results in similar phenotypical resistance. By way of explanation, AmpC producers demonstrate cephamycins resistance and other cephalosporins resistance may be present due to enzyme coproduction. Klebsiella pneumoniae and Escherichia coli studied in this work present the same resistance profile (AMX - AMC, FOX, CAZ) (Table 1), for instance, but they have a different genotype profile. This observation reinforces the importance of associating phenotypic and genotypic methods for the diagnosis of antimicrobial resistance.

The clinical strains were used as donors in the conjugation method in a liquid medium to verify the location of $b l a_{\mathrm{ampC}}$ genes. All bacteria tested were able to transfer $b l a_{\text {ampC }}$ genes to Escherichia coli HB101. The receptor bacteria were a lactose non-fermenter and resistant to streptomycin. Before conjugation, all donors were submitted to streptomycin susceptibility tests, and they were susceptible to it.

Escherichia coli lactose non-fermenter obtained in MacConkey agar with streptomycin and cefoxitin were subjected to identification confirmation by Chromagar Orientation and ID32GN. Then, five colonies of each strain transconjugant were used to disk diffusion method to confirm

Table 1 Phenotypic and genotypic characteristics of isolates producing plasmid AmpC

\begin{tabular}{|c|c|c|c|c|c|c|}
\hline Isolate & Species & Sample & Resistance profile & $\begin{array}{l}\text { Boronic } \\
\text { acid }\end{array}$ & Cloxacillin & $\begin{array}{l}\text { Genotypic profile } \\
\text { (bla) }\end{array}$ \\
\hline 1 & Escherichia coli & Urine & AMX - AMC - FOX - CAZ & Yes & $*$ & AmpC - CIT - CMY \\
\hline $1 \mathrm{~T}$ & Escherichia coli & - & AMX - AMC - FOX - CAZ & Yes & $*$ & AmpC - CIT - CMY \\
\hline 2 & Proteus mirabilis & $\begin{array}{l}\text { Blood } \\
\text { catheter }\end{array}$ & $\begin{array}{l}\text { AMX - AMC - FOX - CAZ - CTX - CEF - } \\
\text { IMI }\end{array}$ & Yes & * & AmpC - CIT - CMY \\
\hline $2 \mathrm{~T}$ & Escherichia coli & - & AMX - AMC - FOX - CAZ - CTX & Yes & $*$ & $\mathrm{AmpC}$ - CIT - CMY \\
\hline 3 & $\begin{array}{l}\text { Klebsiella } \\
\text { pneumoniae }\end{array}$ & Pus & AMX - AMC - FOX - CAZ & Yes & Yes & AmpC - CIT \\
\hline $3 \mathrm{~T}$ & Escherichia coli & - & AMX - AMC - FOX - CAZ & Yes & $*$ & AmpC - CIT \\
\hline 4 & $\begin{array}{l}\text { Klebsiella } \\
\quad \text { pneumoniae }\end{array}$ & Urine & AMX - AMC - FOX - CAZ & Yes & Yes & AmpC - DHA \\
\hline $4 \mathrm{~T}$ & Escherichia coli & - & AMX - AMC - FOX - CAZ & Yes & $*$ & $\mathrm{AmpC}$ \\
\hline 5 & $\begin{array}{l}\text { Klebsiella } \\
\text { pneumoniae }\end{array}$ & Urine & AMX - AMC - FOX - CAZ & Yes & Yes & AmpC - DHA \\
\hline $5 \mathrm{~T}$ & Escherichia coli & - & AMX - AMC - FOX - CAZ & Yes & $*$ & AmpC \\
\hline CMY-2 Control & Escherichia coli & - & AMX - AMC - FOX - CAZ - CEF & Yes & Yes & $\mathrm{AmpC}$ - CIT - CMY \\
\hline $\begin{array}{l}\text { CMY-2 } \\
\text { ControlT }\end{array}$ & Escherichia coli & - & AMX - AMC - FOX - CAZ - CEF & Yes & * & $\mathrm{AmpC}$ - CIT - CMY \\
\hline
\end{tabular}

$T$ transconjugant, $A M X$ amoxicillin, $A M C$ amoxicillin plus clavulanate, $F O X$ cefoxitin, $C A Z$ ceftazidime, $C T X$ ceftriaxone, $C E F$ cefepime, $I M I$ imipenem *There was no visible growth in culture medium 
the phenotypic characteristics observed in donors' bacteria. Only the transconjugant from isolate 2, Proteus mirabilis, do not present the same resistance profile observed in donor. Isolate 2 presented resistance to cefepime and imipenem, but $2 \mathrm{~T}$ did not present this resistance (Table 1), suggesting other mechanism of resistance, such as lack of porins, commonly reported in P. mirabilis [25].

All transconjugants had $\mathrm{pAmpC}$ inhibited by boronic acid. In the cloxacillin inhibition test, it was not possible to determine if this substance could inhibit the pAmpC once all the transconjugants did not grow in MHA with cloxacillin.

The genes $b l a_{\mathrm{ampC}}, b l a_{\mathrm{CIT}}$, and $b l a_{\mathrm{CMY}}$ were transferred to the receptor, demonstrating that these genes are located in a conjugative plasmid. Nevertheless, $b l a_{\mathrm{DHA}}$ was not identified in transconjugants $4 \mathrm{~T}$ and $5 \mathrm{~T}$. This can be justified by the fact that the gene is not inserted in a conjugative plasmid or it can be in other mobile genetic element since it is not a chromosomal AmpC in this specie [5, 10].

ESBL and carbapenemase are widely studied; however, it is necessary to evaluate the $\mathrm{AmpC}$ production in order to understand the risks of the prevalence of this enzyme in and out of hospitals [28]. In the case of $\mathrm{pAmpC}$ production by bacteria, it is necessary to study the best option for antimicrobial therapy [26]. Ribeiro et al. [15] reported pAmpC in nosocomial isolates collected between 2010 and 2013 in north of Portugal. Thus, these genes circulated in hospital environments before 2010 according to our data. These studies demonstrate the importance of more studies to understand epidemiology of pAmpC in Portugal.

\section{Conclusion}

The $b l a_{\mathrm{CIT}}$ and $b l a_{\mathrm{CMY}} \mathrm{pAmpC}$ genes were present in hospitals in the north of Portugal since 2009, and this fact is important because these mobile genes can be passed to other bacteria, including non-nosocomial bacteria. This data is epidemiologically relevant to public health demonstrating the circulation of AmpC genes. Furthermore, it is necessary to implement cAmpC and pAmpC detection tests as routine to select the best option to antimicrobial therapy in these environments, once the $b l a_{\mathrm{AmpC}}$ genes decrease options for antimicrobial therapy.

Funding information This work was financially supported by Ph. D. Sandwich Scholarship (Coordination of Improvement of Higher Level Personnel; CAPES) PDSE 99999.008079/2014-05 (Brazil).

\section{Compliance with ethical standards}

Conflict of interest The authors declare that they have no conflict of interest.

\section{References}

1. Daef EA, Elsherbiny NM (2012) Clinical and microbiological profile of nosocomial infections in adult intensive care units at Assiut University hospitals, Egypt. J Am Sci 8:1239-1250

2. Azimi L, Erajiyan G, Talebi M, Owilia P, Bina M et al (2015) Phenotypic and molecular characterization of plasmid mediated AmpC among clinical isolates of Klebsiella pneumoniae isolated from different hospitals in Tehran. J Clin Diagn Res 9:DC01-DC03

3. Paralikar P, Ingle AP, Tiwari V, Golinska P, Daham H, Rai M (2019) Evaluation of antibacterial efficacy of sulfur nanoparticles alone and in combination with antibiotics against multidrugresistant uropathogenic bacteria. J Envirn Sci Health, Part A 54: 381-390

4. Victorien D, Assogba P, Anago E, Déguénon E, Dapuliga C et al (2020) Enterobacteria responsible for urinary infections: a review about pathogenicity, virulence factors and epidemiology. J Apll Biol Biotechnol 8:117-124

5. Coudron PE (2005) Inhibitor-based methods for detection of plasmid-mediated AmpC $\beta$-lactamases in Klebsiella spp., Escherichia coli, and Proteus mirabilis. J Clin Microbiol 43: 4163-4167

6. Rodríguez-Martínez JM, Poirel L, Nordmann P (2009) Extendedspectrum cephalosporinases in Pseudomonas aeruginosa. Antimicrob Agents Chemother 53:1766-1771

7. Jacoby GA (2009) AmpC $\beta$-lactamases. Clin Microbiol Rev 22(91):161-182

8. Pires J, Taracila M, Bethel CR, Doi Y, Kasraian S, Tinguely R, Sendi P, Bonomo RA, Endimiani A (2015) In vivo evolution of CMY-2 to CMY-33 $\beta$-lactamase in Escherichia coli ST131: characterization of an acquired extended-spectrum AmpC (ESAC) conferring resistance to cefepime. Antimicrob Agents Chemother 59: 7483-7488

9. Bush K, Bradford PA (2020) Epidemiology of $\beta$-lactamaseproducing pathogens. Clin Microbiol Rev 33:e00047-e00019

10. Rensing KL, Abdallah HM, Koek A et al. (2019) Prevalence of plasmid-mediated AmpC in Enterobacteriaceae isolated from humans and from retail meat in Zagazig, Egypt. Antimicrobial resistant infections control 8

11. Husickova V, Cekanova L, Chroma M, Htoutou-Sedlakova M, Hrivoca K, Kolar M (2012) Carriage of ESBL- and AmpCpositive Enterobacteriaceae in the gastrointestinal tract of community subjects and hospitalized patients in the Czech Republic. Biomed Pap Med Fac Univ Palacky Olomouc Czech Repub 156: 348-353

12. Manohara A, Sugumar M, Kumar A, Jose H, Mathai D, ICRMRESBL Study Group (2012) Phenotypic and molecular characterization of AmpC $\beta$-lactamases among Escherichia coli, Klebsiella spp and Enterobacter spp from five. Indian Med Centers Indian J Med Res 135:359-364

13. Albrechtova K, Papousek I, Nys H, Pauly M, Anoh E et al (2014) Low rates of antimicrobial-resistant Enterobacteriaceae in wildlife in Tai National Park, Côte d'Ivoire, surrounded by villages with high prevalence of multiresistant ESBL-producing Escherichia coli in people and domestic animals. PLOS ONE 9:e113548. https://doi. org/10.1371/journal.pone.0113548

14. Meini S, Tascini C, Cei M, Sozio E, Rossolini GM (2019) AmpC $\beta$-lactamase producing Enterobacterales: what a clinician should know. Infection 47:363-375

15. Ribeiro TG, Novais Â, Rodrigues C, Nascimento R, Freitas F, Machado E, Peixe L (2019) Dynamics of clonal and plasmid backgrounds of Enterobacteriaceae producing acquired $\mathrm{AmpC}$ in Portuguese clinical settings over time. Int J Antimicrob Agents 53(5):650-656 
16. CLSI (2020) Performance standards for antimicrobial susceptibility testing; twenty-second informal supplement. CLSI document M100-S22. Clinical and Laboratory Standards Institute, Wayne, PA

17. Mota R, Pinto M, Palmeira J, Gonçalves D, Ferreira H (2018) Letter to the Editor - Intestinal microbiota as a reservoir of extendedspectrum $\beta$-lactamase-producing Escherichia coli: an exploratory study in healthy university students. Journal of Global Antimicrobial Resistance 14:10-11

18. Jones-Dias D, Manageiro V, Ferreira E, Louro D, Antibiotic Resistance Surveillance Program in Portugal (ARSIP) Participants, Caniça M (2014) Diversity of extended-spectrum and plasmid-mediated AmpC $\beta$-lactamases in Enterobacteriaceae isolates from Portuguese health care facilities. J Microbiol 52:496503

19. Sobia F, Shahid M, Singh A, Khan HM, Shukla I, Malik A (2011) Occurrence of bla $\mathrm{ampC}_{\mathrm{an}}$ in cefoxitin-resistant 'Escherichia coli' and 'Klebsiella pneumoniae' isolates from a north Indian tertiary care hospital [online]. N Z J Med Lab Sci 65:5-9

20. Pérez-Pérez FJ, Hanson ND (2002) Detection of plasmid-mediated AmpC $\beta$-lactamase genes in clinical isolates by using multiplex PCR. J Clin Microbiol 40:2153-2162

21. Roche C, Boo TW, Walsh F, Crowley B (2008) Detection and molecular characterisation of plasmidic AmpC $\beta$-lactamases in Klebsiella pneumoniae isolates from a tertiary-care hospital in Dublin, Ireland. Clin Microbiol Infect 14:616-618

22. D'Andrea MM, Nucleo E, Luzzaro F, Giani T, Migliavacca R, Vailati F, Kroumova V, Pagani L, Rossolini GM (2006) CMY16, a novel acquired $A m p C$-type $\beta$-lactamase of the CMY/LAT lineage in multifocal monophyletic isolates of Proteus mirabilis from northern Italy. Antimicrob Agents Chemother 50:618-624

23. Andrade LN, Novais A, Stegani L, Ferreira J, Ribeiro T, Darini AL, Peixe L (2015) High diversity of population structure, virulence factors and mobile genetic elements in CTX-M-, SHV- and CMY-producing extraintestinal Escherichia coli isolates from large hospitals in Brazil. ECCMID, Copenhagen, Dinamarca

24. Goossens H, Grabein B (2005) Prevalence and antimicrobial susceptibility data for extended-spectrum $\beta$-lactamase-and AmpCproducing Enterobacteriaceae from the MYSTIC program in Europe and the United States (1997-2004). Diagn Microbiol Infect Dis 53(4):257-264

25. Girlich D, Bonnin RA, Dortet L, Naas T (2020) Genetics of acquired antibiotic resistance genes in Proteus spp. Front Microbiol 11:256

26. Tamma PD, Doi Y, Bonomo RA, Johnson JK, Simner PJ, Antibacterial Resistance Leadership Group (2019) A primer on AmpC $\beta$-lactamases: necessary knowledge for an increasingly multidrug-resistant world. Clin Infect Dis 69:1446-1455

27. Rizi KS, Mosavat A, Youssefi M, Jamehdar SA, Ghazviniet K et al (2020) High prevalence of blaCMY AmpC beta-lactamase in ESBL co-producing Escherichia coli and Klebsiella spp. Clinical Isolates Northeast Iran J Glob Antimicrob Resist S2213-7165(20):3007530078

28. Reuland EA, Halaby T, Hays JP, Jongh DMC, Snetselaar HDR et al (2015) Plasmid-mediated AmpC: prevalence in communityacquired isolates in Amsterdam, the Netherlands, and risk factors for carriage. PLoS One 10:e0113033

29. Kazemian H, Heidari H, Ghanavati R, Ghafourian S, Yazdani F et al (2019) Phenotypic and genotypic characterization of ESBL, AmpC and carbapenemase- producing Klebsiella pneumoniae and Escherichia coli isolates. Med Princ Pract 28:547-551

Publisher's note Springer Nature remains neutral with regard to jurisdictional claims in published maps and institutional affiliations. 